\title{
Parasitic Currents in Stray Paths of Some Topologies of YASA AFPM Machines: Trend with Machine Size
}

\author{
A. Di Gerlando, Member, IEEE, G. M. Foglia, M. F. Iacchetti, Member, IEEE, R. Perini, Member, IEEE
}

\begin{abstract}
In some topologies of YASA (Yokeless And Segmented Armature) AFPM (Axial Flux Permanent Magnet) Machines, the particular frame structure required to fasten floating teeth can originate stray paths where parasitic currents may circulate. The paper investigates how the amplitude of these currents and the related additional Joule losses depend on the machine size. Reference is made to wind energy generators, rated from some tens of $\mathrm{kWs}$ up to a few MWs. The developed model is mainly based on wind turbine basic data of vendor data sheets, and on the quantities evaluated and tested in two YASA AFPM prototypes, rated 50 and $200 \mathrm{~kW}$.
\end{abstract}

Index Terms - PM machines, Axial Flux Machines, Yokeless And Segmented Armature Machines, Parasitic Current Paths due to Fixing Frame Structure.

\section{NOMENCLATURE}

$A_{c} \quad$ cross section area of the cylindrical spacers;

$A_{g}$ annular air gap cross section area;

$A_{t} \quad$ tooth section area;

$b_{\text {ray }}$ ray breadth;

$b_{\text {rim }}$ rim breadth;

$b_{\text {slot }}$ slot width

$B_{m}$ no-load working value of the PM flux density;

$B_{r} \quad$ PM residual flux density;

$B_{t} \quad$ tooth flux density;

$d_{r} \quad$ ray deflection: $d_{r}=k_{d r} \cdot g_{n}$;

$D_{i} \quad$ AFPM machine core internal diameter;

$D_{e} \quad$ AFPM machine core external diameter;

$D_{t} \quad$ turbine rotor diameter;

$E$ Young modulus;

$E_{A . k}$ EMF of the k-th loop A;

$E_{B . k}$ EMF of the k-th loop B;

$E_{n} \quad$ no-load line-to-line EMF;

$E_{p \ell h}$ rms value of the parasitic loop EMF $h$-th harmonic;

$f_{n}$ rated frequency;

$f_{0} \quad$ reference frequency at a reference turbine power $P_{0}$;

$F$ total mechanical load acting on one ray;

$F_{a x}$ resultant axial force between stator and rotor, due to a variation $\Delta g$ of the air gap;

$F_{\text {ref }}$ reference resultant axial force produced in one air-gap;

Manuscript received June 29, 2015; revised October 9, 2015; accepted November 18, 2015.

Copyright (c) 2015 IEEE. Personal use of this material is permitted. However, permission to use this material for any other purposes must be obtained from the IEEE by sending a request to pubspermissions@ieee.org.

A. Di Gerlando, G.M. Foglia, R. Perini are with the Department of Energy, Politecnico di Milano, Via Lambruschini 4, 20156 Milano, Italy. M.F. Iacchetti is with the School of Electrical and Electronic Engineering, University of Manchester, Sackville Street Building, Manchester, M13 9PL, UK. e-mails: roberto.perini@polimi.it ; gianmaria.foglia@polimi.it ; matteo.iacchetti@manchester.ac.uk ; antonino.digerlando@polimi.it $g_{e} \quad$ equivalent magnetic air gap $=g_{n}+h_{m} / \mu_{r p u}$;

$g_{n} \quad$ rated air gap width;

$h_{m} \quad$ PM axial length;

$I_{A . k} \quad$ current of the k-th loop A;

$I_{B . k} \quad$ current of the k-th loop B;

$I_{c y l .1} \mathrm{rms}$ of the fundamental current flowing in one outer cylindrical spacer;

$I_{\text {loop. } 1} \mathrm{rms}$ of the fundamental current flowing in one loop;

$I_{n} \quad$ rated current;

$I_{\text {ray. } 1} \mathrm{rms}$ of the fundamental current flowing in one ray;

$J \quad$ moment of inertia of a ray $=b_{\text {ray }} \cdot t_{r}{ }^{3} / 12$

$\ell_{a x}$ axial length of the AFPM machine;

$\ell_{m} \quad$ radial size of PMs;

$\ell_{c e}$ lengths of the external cylindrical spacers;

$\ell_{c i} \quad$ lengths of the internal cylindrical spacers;

$L_{p \ell}$ inductance of the parasitic loop;

$\ell_{\text {ray }}$ ray length;

$\ell_{\text {rim }}$ rim length;

$k_{D} \quad$ AFPM diameter ratio: $k_{D}=D_{i} / D_{e}$;

$k_{d r} \quad$ proportionality coefficient: $d_{r}=k_{d r} \cdot g_{n}$;

$k_{g} \quad$ proportionality coefficient: $g_{n}=k_{g} \cdot D_{e}$;

$k_{m} \quad$ proportionality coefficient: $h_{m}=k_{m} \cdot g_{n}$;

$k_{t h}$ harmonic composition factor of 2 nearby teeth fluxes;

$x$ pu synchronous reactance of the AFPM machine;

$N_{n}$ rated rotational speed [rpm];

$N_{t} \quad$ No of teeth per module;

$N_{c} \quad$ No of Geometric Cycles (GCs) per module;

$N_{t c} \quad$ No of teeth per GC $=$ No of coils per GC $=N_{t} / N_{c}$;

$N_{t c p h}$ No of teeth per GC per phase $=$ No of coils in one GC per phase; for a 3-phase machine: $N_{t c p h}=N_{t} /\left(3 \cdot N_{c}\right)$;

$p \quad$ No of poles (No of PMs on each rotor disk face);

$p_{c} \quad$ No of poles per $\mathrm{GC}=$ No of $\mathrm{PMs}$ per $\mathrm{GC}=p / N_{c}$;

$P_{n} \quad$ AFPM machine rated power [kW];

$P_{\text {loss. } 1}$ Joule losses due to first harmonics of parasitic currents;

$P_{t} \quad$ turbine rated power $[\mathrm{kW}]$;

$q \quad$ uniformly distributed force on the ray $=F / \ell_{\text {ray }}$;

$R_{c e}$ resistance of one external spacer;

$R_{c i} \quad$ resistance of one internal spacer;

$R_{\text {ray }}$ resistance of one ray;

$R_{\text {rim }}$ resistance of the rim portion between two rays;

$t_{r} \quad$ ray and rim thickness;

$X_{p \ell n}$ parasitic loop reactance at the rated frequency;

$V_{n} \quad$ Line-to-line rated voltage;

$\alpha_{e} \quad$ slot angle $=\left(2 \pi / N_{t}\right) \cdot(p / 2) ;$

$\alpha_{m}$ p.u. peripheral extension of each PM, ratio between PM width and pole pitch;

$\varphi_{m . t o t}$ absolute value of the total PM flux, equal to the flux of one PM multiplied by the No of poles;

$\varphi_{t} \quad$ tooth flux;

$\varphi_{t . t o t}$ absolute value of the total teeth flux;

$\Phi_{t p}$ no-load peak value of the tooth flux, occurring in the tooth-axis PM-axis alignment condition; 
$\Phi_{t h} \quad h$-th harmonic of the tooth flux;

$\mu_{r p u}$ PM p.u. recoil permeability

$\eta \quad$ AFPM machine efficiency;

$\rho_{s} \quad$ steel resistivity $=1.5 \cdot 10^{-6}[\Omega \cdot \mathrm{m}]$;

$\omega_{n} \quad$ rated angular frequency $=2 \pi f_{n}$;

$\omega_{h} \quad$ angular frequency of $h$-th harmonic $\omega_{h}=h \omega_{n}$.

\section{INTRODUCTION}

A XIAL Flux Permanent Magnet (AFPM) Machines are usually renowned as characterized by greater torque density than radial flux machine configurations [1]. Besides, since a large number of pole pairs can be adopted, AFPM machines are suited for direct drive applications, at low speed, high torque operating conditions, as electromechanical propulsion systems, in-wheel motors, elevators, wind energy generators [2]-[9].

Various AFPM arrangements have been developed [1], [10]-[12]. If a stator core exists, two dispositions can be employed: single-stator double-rotor AFPM machines, i.e. Torus machines, or double-stator single-rotor AFPM machines, i.e. Kaman machines [13].

Frequently the core consists of a rolled laminated cylinder (in such a way that the stacking direction results the radial one). In fact, a core consisting of a laminated ring with axial stacking direction would result stiffer, but at the price of an increase in eddy current losses [14]. If no slots are needed in the laminated cylinder, its manufacture is greatly simplified, as slots would call for punching the iron tape with nonuniform pitch.

To avoid such an issue, an alternative arrangement for Torus kind machines is the so called YASA (Yokeless And Segmented Armature) configuration [15]. As the name indicates, no yoke exists in the core, and the teeth are magnetically independent: thus, the lamination stack is much easier to be manufactured. The YASA layout gives many benefits [16], among which: (a) short end windings and reduced Joule losses, (b) simpler winding assembly and high winding fill factor, (c) very low inductive coupling among phases, with improved fault tolerance capability, (d) minimized winding and core mass.

However, the YASA disposition leads to two further issues. The first one is due to the inherently tapered profile of teeth, demanding variable-width lamination punching. Some manufacturing techniques have been proposed in order to simplify the punching process, such as: milling preassembled parallelepiped lamination stacks [17] or staking alternately-displaced laminations having the same punched profile [18]. An interesting investigation and comparison among several lamination stacking methods is performed in [19]. The second challenge is providing an adequate frame structure to the teeth. In some stator structures, teeth are embedded into a composite-material ring [20], which also houses shaped cooling ducts. Such a solution is also used with SMC teeth [15], [21], [22]. Further arrangements to position and fasten stator teeth rely to radial tie-rods [23] or retentive rings [16]. The former solution can lead to imperfect stator construction [23], whereas the latter seems to be the solution adopted in some patents, [24]-[25], which are used also in commercial YASA motors [26]. In another solution, the central zone of the teeth is unwound, so they can be inserted in a bulk retaining disk [27]. However, all the aforementioned solutions can be used just in case of medium-low rating machines.

For medium-high rating machines, an alternative stator structure consists of hollow and rayed plate pairs assembled with spacers and pre-tensioned tie rods to provide adequate stiffness. As detailed in Fig. 1, each tooth is fastened between contiguous rays. This disposition has been adopted for two prototypes of a three phase AFPM synchronous machine (SM) (Fig. 1c and Figs. 2, 3), both employed as wind energy generators. Figs. 2, 3 show a picture of the machines, while Tables I, II resume their main data (see also [18], [28], [29]).

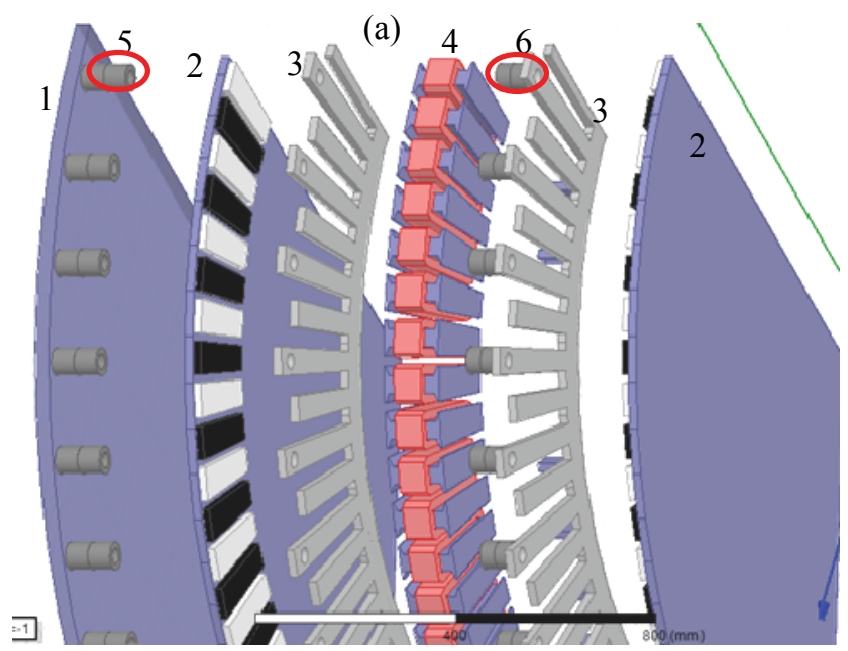

(b)
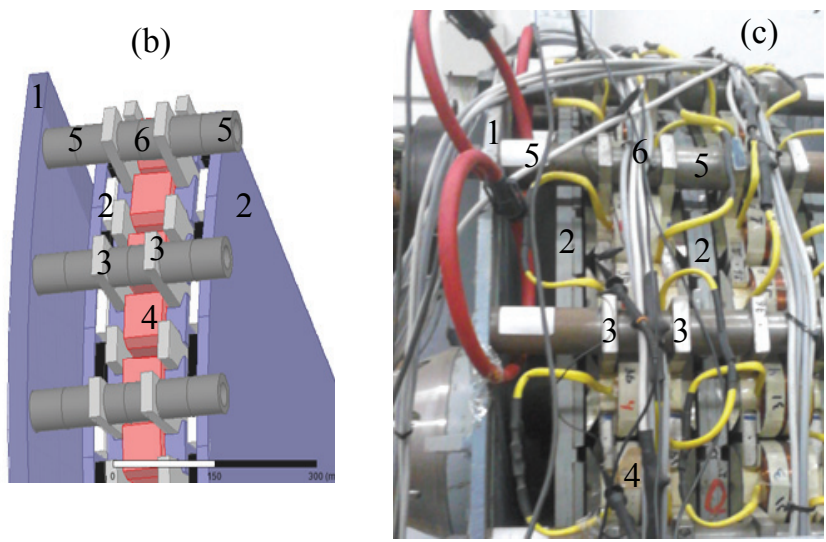

Fig. 1. Exploded (a) and compact (b) views of one sector of half of the YASA AFPM prototype (c) whose fixing structure uses rays and tie-rods 1: stator plate; 2: rotor disks with PMs; 3: ray structures; 4: wound teeth; 5 , 6: outer and inner spacers respectively, in which tie-rods are threaded.

Unfortunately, the overall frame structure inherently creates parasitic loops through tie-rods, rays, and plates, in which electro-motive forces (EMFs) are induced during the $\mathrm{PM}$ rotor rotation. Even if the induced parasitic EMFs have very low amplitudes, the parasitic loops impedance is very low too, thus the parasitic currents may easily reach hundreds of amperes. Preventing the parasitic current circulation is technically challenging and costly, due to the narrow mechanical tolerances to be guaranteed in the machine construction. Insulations between contact surfaces of spacers and plates require high-stiffness, dimensionallystable and corrosion-proof materials and careful assembly procedures as well.

The genesis mechanism of parasitic currents in the frame structure has been studied [30], [31], and a model for predicting parasitic currents has been developed and 
validated by some measurements on prototypes. However, no discussion and calculations of the additional Joule losses produced by parasitic currents have been provided in [30] and [31]. In addition, [30] and [31] do not analyze the impact of the scale effects on parasitic currents and related losses. Nevertheless, the full understanding of the scale effects is crucial for the proper design of high-rating YASA AFPM machines. This paper addresses all these pending issues by investigating the dependence of the parasitic current amplitude on the machine size and discussing the impact on additional Joule losses. The outcomes of such investigations provide the basis to evaluate the advisability of insulating layers at the contact interfaces between spacers and rays or plates, depending on the scale effects. To this purpose, the parameters of the parasitic path branches and the machine construction and operation quantities are preliminarily expressed as a function of the rated power, by invoking general sizing criteria and rather usual characteristic aspect ratios extrapolated from existing machine designs. They include two constructed prototypes of different scale ( $50 \mathrm{~kW} / 70 \mathrm{rpm}$ and $200 \mathrm{~kW} / 35 \mathrm{rpm})$ and the design of a third machine (2MW/17 rpm, Table III).

All the predictions regarding the amplitude of the parasitic currents and the related additional Joule losses are compared with the measurements on the two prototypes. In order to obtain experimental evidence of the parasitic currents and the related additional Joule losses, the two considered prototypes have been purposely built without any frame insulation.

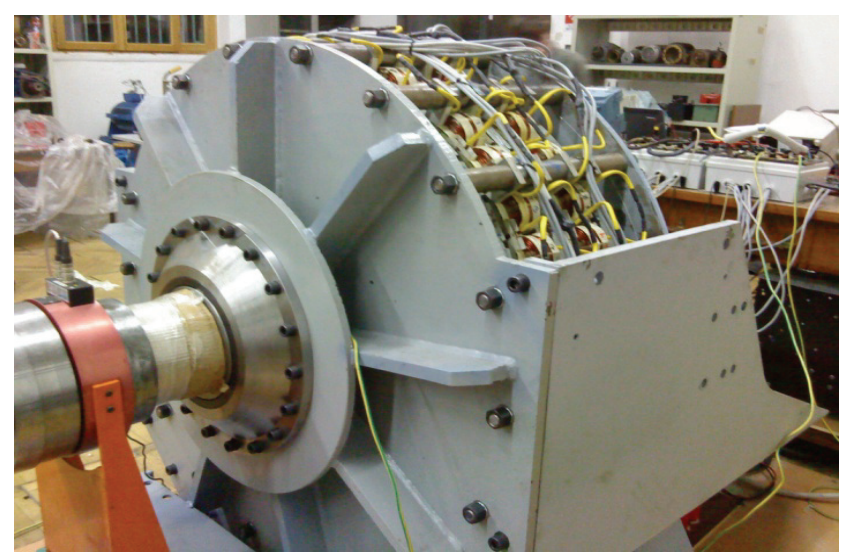

Fig. 2. Photograph of the $50 \mathrm{~kW} / 70 \mathrm{rpm}$ three phase AFPMSG prototype.

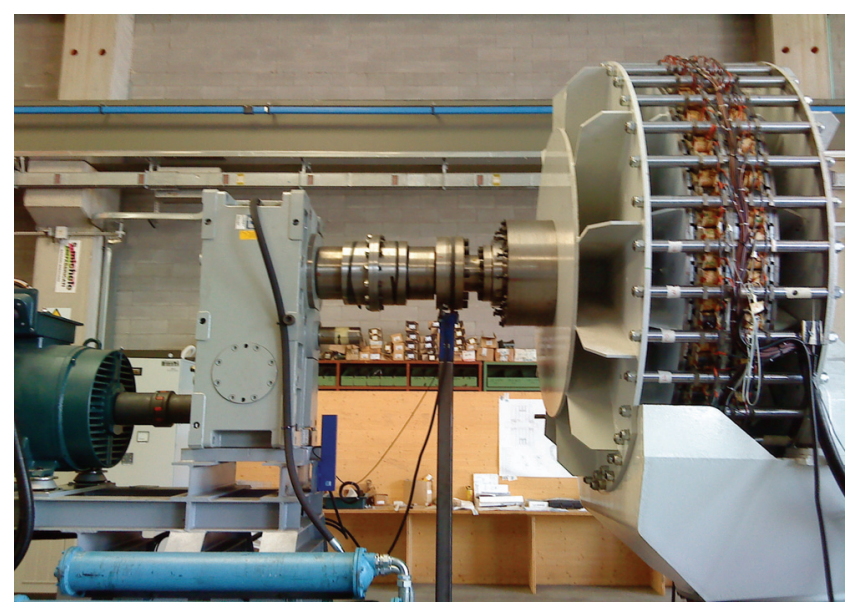

Fig. 3. Photograph of the $200 \mathrm{~kW} / 35 \mathrm{rpm}$ three phase AFPMSG prototype.
The paper is structured as follows. Sec. II resumes the genesis of the parasitic currents. Sec. III reports the results of a survey among the commercial turbine data sheets, to gain a relation between the turbine power and both the turbine speed and the maximum generator external diameter. Based on the two prototypes, Sec. IV investigates the relation between the power and the main electro-mechanical quantities of the generator (air gap, poles number, cycle number, teeth number). In Sec. V, the geometrical sizes involved in the evaluation of the resistances of the parasitic paths are expressed as a function of the power: this way, the reactance and the resistances can be evaluated as a function of the machine power. In Sec. VI a single-loop simplified model is developed, to quickly estimate the rms value of the parasitic current. Finally, in Sec. VII the parasitic EMFs and currents are evaluated by means of the model, and compared with the values measured on the prototypes.

TABLE I

MAIN DESIGN DATA OF THE 50 KW/70 RPM 3-PHASE AFPMSG PROTOTYPE

\begin{tabular}{ll}
\hline Line-to-line rated Voltage $V_{n}$, no-load e.m.f. $E_{n}[\mathrm{~V}]$ & 625,750 \\
Rating $P_{n}[\mathrm{~kW}]$, speed $N_{n}[\mathrm{rpm}]$, frequency $f_{n}[\mathrm{~Hz}]$ & $50,70,22.17$ \\
Rated current $I_{n}[\mathrm{~A}]$, eff. $\eta[\%]$, reactance $x[\mathrm{pu}]$ & $46.3,92.6,0.50$ \\
Pole No $=$ PM No $p$, teeth No $N_{t}$ & 38,36 \\
Cycle No $N_{c}$, teeth $/$ cycle/phase $N_{t c p h}$, pole/cycle $p_{c}$ & $2,6,19$ \\
Ext. diam. $D_{e}$, int. diam. $D_{i}$, axial length $\ell_{a x}[\mathrm{~mm}]$ & $1100,914,330$ \\
\hline
\end{tabular}

TABLE II

MAIN DeSign DATA OF THE 200 KW/35 RPM 3-PhASE AFPMSG PROTOTYPE

\begin{tabular}{ll}
\hline Line-to-line rated Voltage $V_{n}$, no-load e.m.f. $E_{n}[\mathrm{~V}]$ & 624,718 \\
Rating $P_{n}[\mathrm{~kW}]$, speed $N_{n}[\mathrm{rpm}]$, frequency $f_{n}[\mathrm{~Hz}]$ & $200,35,22.75$ \\
Rated current $I_{n}[\mathrm{~A}]$, eff. $\eta[\%]$, reactance $x[\mathrm{pu}]$ & $185,93.3,0.34$ \\
Pole No $=$ PM No $p$, teeth No $N_{t}$ & 78,72 \\
Cycle No $N_{c}$, teeth/cycle/phase $N_{t c p h}$, pole/cycle $p_{c}$ & $6,4,13$ \\
Ext. diam. $D_{e}$, int. diam. $D_{i}$, axial length $\ell_{a x}[\mathrm{~mm}]$ & $2100,1680,376$ \\
\hline
\end{tabular}

TABLE III

MAIN DESIGN DATA OF THE 2 MW/17 RPM 3-PHASE AFPMSG DESIGN

Line-to-line rated Voltage $V_{n}$, no-load e.m.f. $E_{n}[\mathrm{~V}] \quad 624,828$

Rating $P_{n}[\mathrm{~kW}]$, speed $N_{n}[\mathrm{rpm}]$, frequency $f_{n}[\mathrm{~Hz}] \quad 2000,17,14.73$

Rated current $I_{n}$ [A], eff. $\eta[\%]$, reactance $x[\mathrm{pu}] \quad 1851,94.3,0.59$

Pole No $=$ PM No $p$, teeth No $N_{t}$

Cycle No $N_{c}$, teeth/cycle/phase $N_{\text {tcph }}$, pole/cycle $p_{c} \quad 8,4,13$

$\begin{array}{ll}\text { Ext. diam. } D_{e} \text {, int. diam. } D_{i} \text {, axial length } \ell_{a x}[\mathrm{~mm}] & 5000,3600,589\end{array}$

\section{GENESIS OF THE PARASITIC CURRENTS}

Fig. 1a shows that the ray structure is made by the rays and by an internal rim which connects them; the same figure shows that long and short rays are alternatively disposed. Only long rays are connected by tie-rods, whereas short rays are floating. Two consecutive long rays, together with the portion of internal rim between them, form an open loop, which is closed by the tie-rods and the stator plate (Fig. 4).

Such parasitic loops embrace two teeth, thus they link the resultant flux of two adjacent teeth.

In no-load operation, fluxes in adjacent teeth are almost opposite each other, because the tooth pitch is close to the PM pitch; however, the resultant flux is not zero. Due to the PM rotation, this parasitic loop flux linkage is alternate: therefore it induces EMFs in the loops.

In the following, the analysis is developed just considering the machine no-load operation. This is well suited to correctly predict parasitic currents; in fact:

- most parasitic loops (sometimes all of them, depending on the winding layout) embrace two coils belonging to the 
This is the author's version of an article that has been published in this journal. Changes were made to this version by the publisher prior to publication. The final version of record is available at http://dx.doi.org/10.1109/TIE.2015.2511086

IEEE TRANSACTIONS ON INDUSTRIAL ELECTRONICS

same phase: however, due to their reverse series connection, even in loaded operation the armature reaction MMF acting in each loop has a zero resultant;

- for the few parasitic loops whose embraced coils belong to different phases, the resultant MMF amplitude equals that of one coil, due to a 120 deg phase displacement;

- in loaded rated conditions, the coil MMF amplitude is roughly $1 / 10$ of the equivalent PM MMF.

The soundness of this approach has been confirmed by some tests, which showed that parasitic currents and related losses do not significantly increase in load operation compared with no load operation.

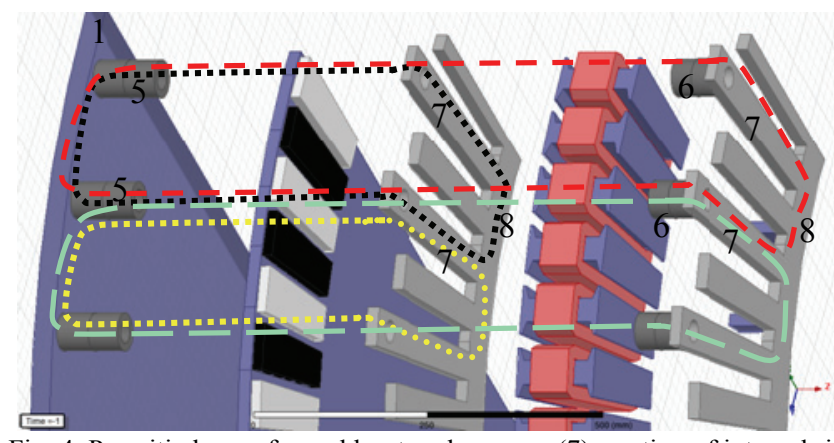

Fig. 4. Parasitic loops, formed by: two long rays (7), portion of internal rim between them (8), spacers (5 outer, or 6 inner), stator plate (1).

\section{SPEED AND DiAmEter VERSUS MACHINE RATING}

Based on the available turbine data sheets, a survey has been performed to gain the trend of both the turbine rated speed $N_{n}$ and the turbine rotor diameter $D_{t}$ versus the turbine power $P_{t}$.

Figs. 5a-5b show the found data points, together with the adopted fitting equations:

$$
\begin{gathered}
N_{t}\left(P_{t}\right)=213.79 \cdot\left(P_{t}[\mathrm{~kW}]\right)^{-0.326}[\mathrm{rpm}] \\
D_{t}\left(P_{t}\right)=3.383 \cdot\left(P_{t}[\mathrm{~kW}]\right)^{0.4213}[\mathrm{~m}]
\end{gathered}
$$

Starting from the turbine diameter, and by adopting suited reduction coefficients, the AFPM generator external diameter $D_{e}$ can be estimated, as a function of the power. In particular, on the basis of the average manufacturers' data, the nacelle diameter has been assumed $7.5 \%$ of $D_{t}$, and $D_{e}$ equal to $80 \%$ of the nacelle diameter, therefore:

$$
D_{e}\left(P_{t}\right)=0.06 \cdot D_{t}\left(P_{t}[\mathrm{~kW}]\right) \quad[\mathrm{m}] .
$$

In Fig. 5c, the fitting curves $N_{t}\left(\mathrm{P}_{t}\right)$ and $D_{e}\left(P_{t}\right)$ by (1) and (2) are shown, together with the corresponding points for the power rating values $P_{t}=50,200,2000 \mathrm{~kW}$. Solid markers ( $\square$ and $\boldsymbol{\Delta}$, respectively for $N_{n}$ and $D_{e}$ ) represent the actual values of the prototypes $(50,200 \mathrm{~kW})$, while the empty markers $(\square, \Delta)$ refer to the corresponding values of a design for a $2 \mathrm{MW}$ machine. It can be seen that the values fairly agree with the fitting equations trend.

\section{Main Electro-Mechanical Quantities Versus MACHINE RATING}

Based on the sizes of the two prototypes, the relation among the machine power rating $P_{t}$ and the main electromechanical quantities is investigated.

First of all, the following proportionality laws are assumed: air gap $g_{n} \propto D_{e}$; PM axial width $h_{m} \propto g_{n}$ :

$$
\begin{gathered}
g_{n}\left(P_{t}\right)[\mathrm{mm}]=k_{g} \cdot\left(D_{e}\left(P_{t}\right)[\mathrm{m}]\right), \quad k_{g}=2[\mathrm{~mm} / \mathrm{m}] \\
h_{m}\left(P_{t}\right)[\mathrm{mm}]=k_{m} \cdot g_{n}\left(P_{t}\right), \quad k_{m}=3
\end{gathered}
$$

The rated generator frequency $f_{n}$ is assumed dependent on $P_{t}$ on the basis of the relation

$$
f_{n}\left(P_{t}\right)=f_{0} \cdot \exp \left(-P_{t} / P_{0}\right)
$$

where $f_{0}=23.0 \mathrm{~Hz}, P_{0}=4686 \mathrm{~kW}$; such values allow to fairly fit the prototype data ( $f_{n}$ in Tables I and II) together with a plausible frequency value for a high rated designed generator(15 Hz@2 MW).
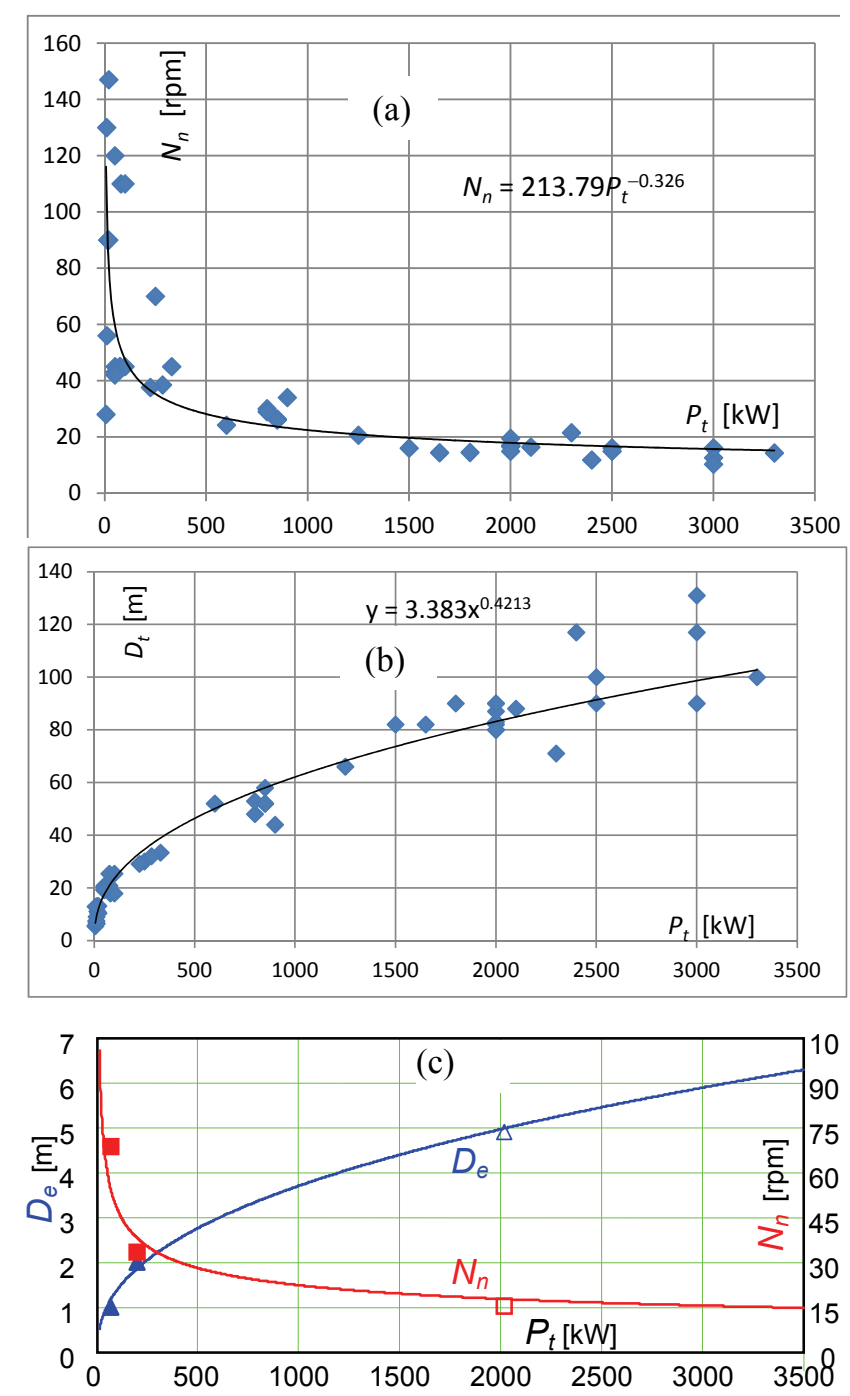

Fig. 5. Curves as a function of the rated turbine power $P_{t}[\mathrm{~kW}]$ :

(a) top: turbine rated speed $N_{n}[\mathrm{rpm}]$ as a function of $P_{t}$ (vendors' data); (b) middle: turbine diameter $D_{t}[\mathrm{~m}]$ as a function of $P_{t}$ (vendors' data);

(c) bottom: fitting equations of the turbine rated speed $N_{n}$ and of the AFPM machine external diameter $D_{e}[\mathrm{~m}]$ as a function of $P_{t}$; the points give the corresponding actual values of constructed prototypes (full points: $P_{t}=50$, $200 \mathrm{~kW}$ ) and of a designed machine (empty marker: $P_{t}=2 \mathrm{MW}$ ).

According to the generator operation principle ([18],[28]), one of the most important machine characteristic is the number of tooth coils per cycle per phase $N_{t c p h}$ (i.e.: the number of series connected coils in one cycle, belonging to one phase). It does not depend on the machine size, but it is related to the electromagnetic operation: its meaning is similar to the number of slot/pole/phase in distributed winding machine (the higher $N_{t c p h}$, the lower the EMF waveform distortion). 
$N_{\text {tcph }}$ is preferably an even number, and its most common values are 4 or 6 ; in fact, the $50 \mathrm{~kW}$ and $200 \mathrm{~kW}$ prototypes adopt $N_{t c p h}=6$ and 4 respectively. In the following, $N_{t c p h}$ will be assumed as a parameter for the generator design, and both cases $\left(N_{t c p h}=4 ; 6\right)$ will be considered.

Based on the design procedure ( [18], [28] ), the generator pole number $p$, cycle number $N_{c}$ and teeth number $N_{t}$, can be expressed as a function of $f_{n}$ and $P_{t}$, with $N_{t c p h}$ as parameter:

$$
\begin{aligned}
& p\left(f_{n}, P_{t}\right)=\text { Round }\left(\frac{120 \cdot f_{n}}{N_{n}\left(P_{t}\right)}, 2\right) \\
& N_{c}\left(f_{n}, P_{t}, N_{t c p h}\right)=\text { Round }\left(\frac{p\left(f_{n}, P_{t}\right)}{3 \cdot N_{t c p h}+1}, 1\right) \\
& N_{t}\left(f_{n}, P_{t}, N_{t c p h}\right)=p\left(f_{n}, P_{t}\right)-N_{c}\left(f_{n}, P_{t}, N_{t c p h}\right)
\end{aligned}
$$

where the function $\operatorname{Round}(x, y)$ rounds the number $x$ as the nearest multiple of $y$.

By substituting (4) in (5), the dependence on $f_{n}$ disappears, and the quantities depend only on the power $P_{t}$ (and on the parameter $N_{t c p h}$ ).

\section{GEOMETRICAL SIZES INVOLVED IN THE PARASITIC PATHS RESISTANCES AND REACTANCE}

Fig. 4 shows that four branches are involved in the parasitic loops: the long rays (element number 7), the portion of internal rim between them (8), the cylindrical spacers ( 5 outer, 6 inner). Fig. 6 shows these four elements and their geometrical dimensions, which are needed for the evaluation of the parasitic paths resistances: lengths of the external and internal cylindrical spacers $\left(\ell_{c e}, \ell_{c i}\right)$ and their section area $\left(A_{c}\right)$, ray and rim length, breadth, thickness $\left(\ell_{\text {ray }}\right.$, $\left.\ell_{\text {rim }}, b_{\text {ray }}, b_{\text {rim }}, t_{r}\right)$.

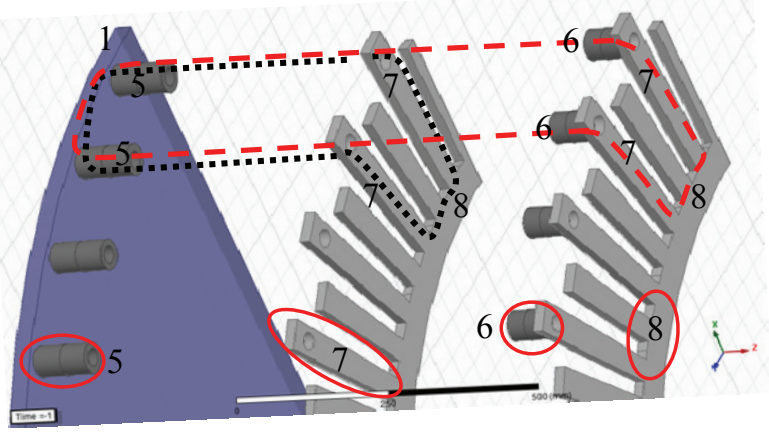

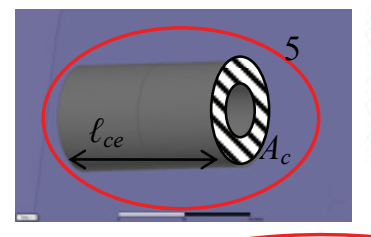

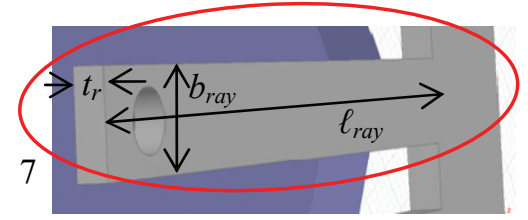

Fig. 6. Top: branches involved in the parasitic loops: the long rays (element number 7), the portion of internal rim between them (8), the cylindrical spacers ( 5 outer, 6 inner). Bottom: geometrical dimensions of the four elements $5,6,7,8$.

In the following, all these dimensions are expressed as a function of the machine power. The stator plate (element 1 in Fig.s 4 and 6) is not considered, since it offers a negligible resistance to the parasitic currents, compared with the resistances of the other involved branches.

\section{A. Radial size $\ell_{m}$ of PMs and teeth .}

The Radial size $\ell_{m}$ can be expressed as

$$
\ell_{m}\left(P_{t}\right)=\left(1-k_{D}\right) \cdot D_{e}\left(P_{t}\right) / 2
$$

where $k_{D}=D_{i} / D_{e}$, and $D_{i}=$ AFPM generator internal diameter. On the basis of the values adopted for the two prototypes, in this analysis it is assumed $k_{D}=0.75$.

\section{B. Ray width $b_{\text {ray }}$.}

The annular air gap section area $A_{g}$ can be expressed as

$$
A_{g}=\frac{\pi}{4} D_{e}^{2}\left(1-k_{D}^{2}\right)
$$

Let us indicate with $\alpha_{m}$ the p.u. peripheral extension of each PM (i.e.: the ratio between the PM width and the polar pitch), and with $B_{m}$ the PM working value of the no-load flux density. The absolute value of the total PM flux $\varphi_{m . t o t}$ (equal to the flux of one PM multiplied by the No of poles) can be obtained by multiplying $A_{g}$ times $\alpha_{m}$ and $B_{m}$; by neglecting the PM leakage flux, $\varphi_{m \text { mtot }}$ can be considered equal to the absolute value of the total teeth flux $\varphi_{\text {t.tot }}$; therefore, the flux $\varphi_{t}$ of one tooth can be obtained by dividing $\varphi_{\text {t.tot }}$ by the teeth No $N_{t}$; finally, by dividing $\varphi_{t}$ by the tooth flux density $B_{t}$, the tooth section area $A_{t}$ follows:

$$
A_{t}=\frac{\pi}{4} D_{e}^{2}\left(1-k_{D}^{2}\right) \alpha_{m} B_{m} \frac{1}{N_{t}} \frac{1}{B_{t}}
$$

The section area of one inter-teeth slot can be expressed as $A_{g} / N_{t}-A_{t}$, and dividing it by $\ell_{m}$ gives the slot width $b_{\text {slot }}$. Since the ray width $b_{\text {ray }}$ equals the slot width, we obtain

$$
b_{\text {ray }}=\frac{\pi}{4} D_{e}^{2}\left(1-k_{D}^{2}\right) \frac{1}{N_{t}}\left[1-\alpha_{m} \frac{B_{m}}{B_{t}}\right] \frac{1}{\ell_{m}}
$$

By putting (6) in (9), we gain

$$
b_{\text {ray }}\left(P_{t}, N_{t c p h}\right)=\frac{\pi}{2} D_{e}\left(P_{t}\right) \cdot\left(1+k_{D}\right) \frac{1}{N_{t}\left(P_{t}, N_{t c p h}\right)}\left[1-\alpha_{m} \frac{B_{m}}{B_{t}}\right]
$$

According to the prototype design values, in this analysis it is assumed $\alpha_{m}=0.8, B_{m}=0.75(\mathrm{~T}), B_{t}=1.75(\mathrm{~T})$.

\section{Ray and rim thickness $t_{r}$.}

In an ideal AFPM machine, the distance between the rotor and the stator is the same all over the air gap, thus the net axial force between the stator and the rotor is zero; unfortunately, in actual machines, manufacturing imperfections always exist, therefore a resultant attraction force occurs between the stator teeth and the rotor disk. This force acts on each ray, which behaves as a fixed-end beam, and tends to bend, reducing the air gap, with a contact risk. A simplified static scheme for the evaluation of the ray deflection is provided in Fig. 7.

Being the two rims bolted together through an inner spacer array (not shown in Fig. 6), such an assembly is treated as a rigid body, suspended to the cylindrical spacers of the stator frame by rays. The additional flexibility inherently due to the rim plates is roughly accounted for by placing virtual hinges between rays and rims. Rigid stator 
spacer and tie rod assemblies are assumed, as their bending stiffness is much higher than the ray one.
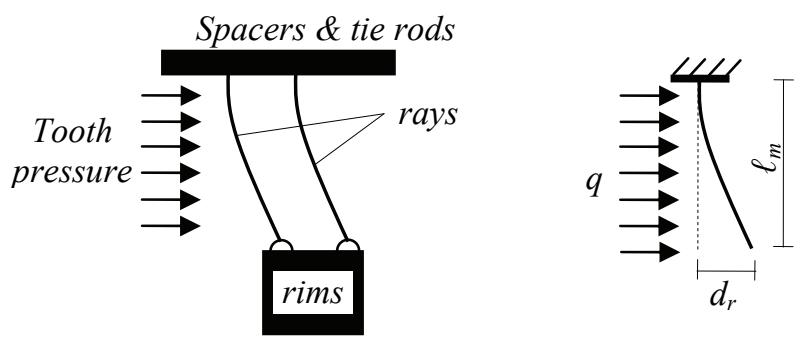

Fig. 7. Static scheme of the stator rim - ray and spacer assembly for the ray deflection estimation.

The ray thickness $t_{r}$ must be high enough to limit the ray deflection $d_{r}$ to a fraction $k_{d r}$ of the rated air gap $g_{n}$ (i.e.: $d_{r}=$ $k_{d r} \cdot g_{n}$ ). By imposing a limit value of $k_{d r}$, the minimum $t_{r}$ value can be obtained. In fact, the deflection $d_{r}$ of the equivalent fixed-end beam under a uniformly distributed force $q$ is expressed by

$$
d_{r}=\frac{1}{8} \frac{q \ell_{m}^{4}}{E J}
$$

By rearranging (11) with $q=F / \ell_{m}$ and $J=b_{\text {ray }} \cdot t_{r}{ }^{3} / 12$, the thickness $t_{r}$ is obtained:

$$
t_{r}=\left\{\frac{3}{2 E} \frac{F \cdot \ell_{m}^{3}}{\left(k_{d r} \cdot g_{n}\right) \cdot b_{r a y}}\right\}^{\frac{1}{3}}
$$

Since there are two spokes in parallel (spoke pair) which support two teeth and since there is one floating spoke pair every two, $F$ is the force acting on a tooth. This can be expressed as $F_{a x} / N_{t}$, where $F_{a x}$ is the resultant axial force acting between the stator and the rotor due to a variation $\Delta g$ of the air gap $(+\Delta g$ in one side air gap and $-\Delta g$ in the other one). The variation $\Delta g$ is assumed as caused by an axial displacement of the rotor disk, occurred during the assembling procedure. The study presented in [32] showed that in this situation, if both $\Delta g$ and $F_{a x}$ are expressed in p.u. values (i.e.: $\Delta g_{p u}=\Delta g / g_{n} ; F_{a x . p u}=F_{a x} / F_{r e f}$ ), the p.u. force equals the p.u. air gap variation, that is $F_{a x . p u}=\Delta g_{p u}$. In [32], the reference force $F_{\text {ref }}$ is the magnetic axial force developed in one air gap, due to the air gap flux density $B_{g}=$ $\alpha_{m} \cdot B_{m}$ :

$$
F_{r e f}=\frac{B_{g}^{2}}{2 \cdot \mu_{0}} A_{g}
$$

Therefore, we obtain

$$
t_{r}\left(P_{t}\right)=\left\{\frac{3}{32 \cdot E} \frac{\left(\alpha_{m} B_{m}\right)^{2}}{2 \cdot \mu_{0}} \frac{\Delta g_{p u}}{k_{d r} g_{n}\left(P_{t}\right)} \frac{\left[D_{e}\left(P_{t}\right) \cdot\left(1-k_{D}\right)\right]^{4}}{1-\frac{\alpha_{m} B_{m}}{B_{t}}}\right\}^{\frac{1}{3}}
$$

In this analysis, it is assumed $\Delta g_{p u}=0.2, k_{d r}=0.1, E=$ $220,000 \mathrm{MPa}$ (rays are made of C40 steel).

\section{Other dimensions}

Based on the sizing of the two prototypes, the following geometrical relations are assumed:

$$
\begin{gathered}
\ell_{\text {ray }}\left(P_{t}, N_{t c p h}\right)=\ell_{m}\left(P_{t}\right)+2 \cdot b_{\text {ray }}\left(P_{t}, N_{t c p h}\right) \\
b_{\text {rim }}\left(P_{t}\right)=0.03 \cdot D_{e}\left(P_{t}\right)
\end{gathered}
$$

$$
\begin{gathered}
\ell_{r i m}\left(P_{t}, N_{t c p h}\right)=\frac{0.9 \cdot k_{D} \cdot D_{e}\left(P_{t}\right)}{N_{t}\left(P_{t}, N_{t c p h}\right)} \\
\ell_{c i}=0.1 \mathrm{~m}(\text { constant }) \\
\ell_{c e}\left(P_{t}\right)=0.1 \cdot D_{e}\left(P_{t}\right) \\
A_{c}\left(P_{t}, N_{t c p h}\right)=0.6 \cdot b_{r a y}\left(P_{t}, N_{t c p h}\right)^{2}
\end{gathered}
$$

\section{E. Reactance and resistances expressions.}

The inductance $L_{p \ell}$ of the parasitic loop is in practice dependent on the permeance of the air gap facing two adjacent teeth. Thus, it can be expressed as $L_{p \ell}=\mu_{0} \cdot\left(2 \cdot A_{g} / N_{t}\right)$ $/ g_{e}$, where $g_{e}$ is the equivalent magnetic air gap $g_{e}=g_{n}+h_{m}$ $/ \mu_{r p u}$, and $\mu_{r p u}$ is the PM p.u. recoil permeability. Therefore, at the rated frequency $f_{n}$, the parasitic loop reactance $X_{p \ell n}$ is

$$
X_{p \ell n}\left(P_{t}, N_{t c p h}\right)=\frac{2 \pi f_{n}\left(P_{t}\right) \cdot \mu_{0} \cdot 2 \pi / 4 D_{e}\left(P_{t}\right)^{2}\left(1-k_{D}{ }^{2}\right)}{N_{t}\left(P_{t}, N_{t c p h}\right)\left[g_{n}\left(P_{t}\right)+h_{m}\left(P_{t}\right) / \mu_{r p u}\right]}
$$

Indicated with $\rho_{s}$ the steel resistivity $\left(\rho_{s}=1.5 \cdot 10^{-6} \Omega \cdot \mathrm{m}\right)$, the resistances of the four branches of Fig. 6 are as follows:

$$
\begin{gathered}
R_{r a y}\left(P_{t}, N_{t c p h}\right)=\rho_{s} \frac{\ell_{r a y}\left(P_{t}, N_{t c p h}\right)}{b_{r a y}\left(P_{t}, N_{t c p h}\right) \cdot t_{r}\left(P_{t}\right)} \\
R_{r i m}\left(P_{t}, N_{t c p h}\right)=\rho_{s} \frac{0.5 \cdot \ell_{r i m}\left(P_{t}, N_{t c p h}\right)}{b_{r i m}\left(P_{t}\right) \cdot t_{r}\left(P_{t}\right)} \\
R_{c e}\left(P_{t}, N_{t c p h}\right)=\rho_{s} \frac{\ell_{c e}\left(P_{t}, N_{t c p h}\right)}{A_{c}\left(P_{t}, N_{t c p h}\right)} \\
R_{c i}\left(P_{t}, N_{t c p h}\right)=\rho_{s} \frac{\ell_{c i}\left(P_{t}, N_{t c p h}\right)}{A_{c}\left(P_{t}, N_{t c p h}\right)} .
\end{gathered}
$$

We remark that all the relations (1)-(15), which give the trend of the geometrical sizes with the power, are based on the prototypes sizing, but cannot match exactly the actual geometrical sizes of the prototypes; this implies that the reactance and resistances expressions (16)-(17) give different values, depending on which geometrical sizes are used, namely the sizes obtained by the model (1)-(15), or the prototypes actual sizes. Table IV reports the values of the parasitic loop reactance $X_{p \ell n}$ (at the rated frequency $f_{n}$ ) and of the branch resistances, evaluated in the two cases: the data labeled "model" are obtained by putting in (16)-(17) the geometrical sizes given by (1)-(15), whereas the data labeled "prototype" are obtained by putting in (16)-(17) the prototypes actual sizes. Note that the model and the prototype data are rather different each other, but the difference is not always in the same way: most times the model values are higher, but for $R_{\text {rim }}$ the opposite occurs.

TABLE IV

PaRASitic LoOP REACTANCE (16) AND BRANCH ReSistanCES (17)

COMPARISON BETWEen THE VALUES GaINED By USING THE SizeS OBTAINED BY THE MODEL (1)-(15) AND THE PROTOTYPE ACTUAL SizES.

\begin{tabular}{c|c|c|c|c|c|c}
\hline \hline \multicolumn{2}{c|}{} & \multicolumn{5}{|c}{ resistances and reactance $[\mu \Omega]$} \\
\hline \multirow{2}{*}{$50 \mathrm{~kW}$} & $R_{\text {ray }}$ & $R_{r y m}$ & $R_{c e}$ & $R_{c i}$ & $X_{p \ell n}$ \\
\cline { 2 - 7 } & $\begin{array}{c}\text { model } \\
\left(N_{t c p h}=6, P_{t}=50 \mathrm{~kW}\right)\end{array}$ & 1024 & 52 & 141 & 134 & 365 \\
\hline \multirow{2}{*}{$200 \mathrm{~kW}$} & prototype & 289 & 83 & 125 & 65 & 211 \\
\cline { 2 - 7 } & $\begin{array}{c}\text { model } \\
\left(N_{\text {tcph }}=4, P_{t}=200 \mathrm{~kW}\right)\end{array}$ & 736 & 20 & 172 & 91 & 428 \\
\cline { 2 - 7 } & prototype & 493 & 89 & 195 & 57 & 288 \\
\hline \hline
\end{tabular}


Fig. 8 shows graphically the trends of these quantities (eq.s (16)-(17), continuous lines) as a function of the machine power rating; also the prototype values are highlighted (markers). Only the results of the $200 \mathrm{~kW}$ prototype are shown, since the $50 \mathrm{~kW}$ case exhibits similar trends and level of agreement between model and prototype values.

In Fig. 8 and in some following trend analysis diagrams, discontinuities are introduced by Round functions used in equation (5) to force $p$ and $N_{c}$ to be integer numbers.

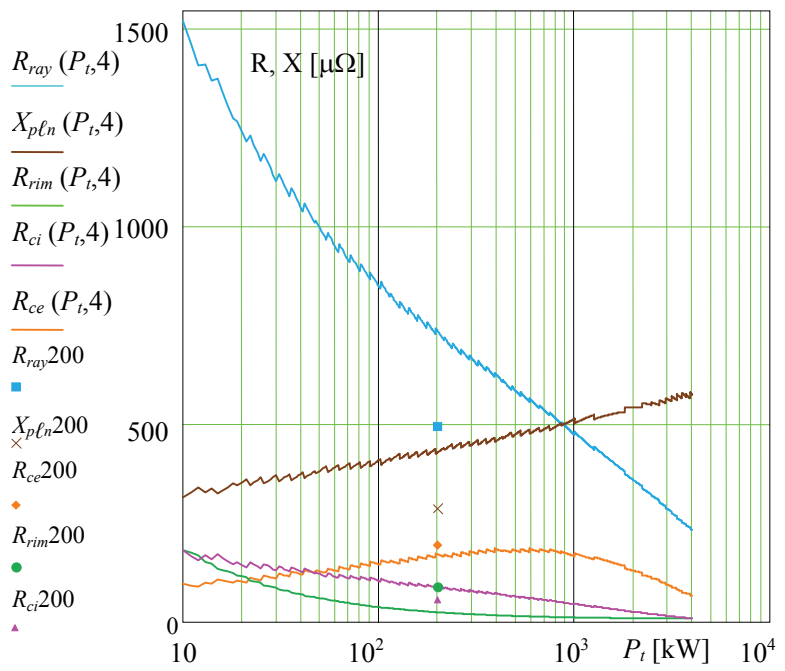

Fig. 8. Trends of the parasitic loop reactance and of the branch resistances (16)-(17) as a function of the machine power rating (continuous lines), together with the $200 \mathrm{~kW}$ prototype values (markers).

\section{Single Loop Parasitic Path Model}

Fig. 9 shows the resistances which form the $k$-th couple ( $k A$ and $k B$ ) of the parasitic loops. In it, both the symbols of the loop inductance $\left(L_{p \ell}\right)$ and of the EMF sources $\left(e_{A k}\right.$ and $\left.e_{B k}\right)$ do not appear, since they both cannot be attributed to a particular loop branch, but are related to the loop itself. The phasors of the loop currents $\bar{I}_{A . k}$ and $\bar{I}_{B . k}$ are also shown.

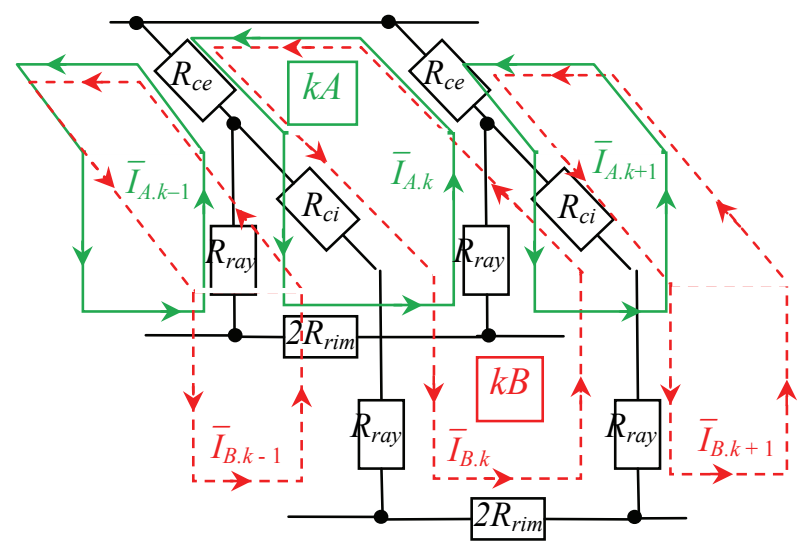

Fig. 9. Resistive elements of the k-th couple of parasitic loops shown in Fig. 6 (loops $k A$ and $k B$ ) and phasors of the loop currents $\bar{I}_{A . k}$ and $\bar{I}_{B . k}$. The circuit symbols for inductances and EMFs are not drawn, because they cannot be attributed to particular branches, but to the loops only.

In the phasor domain, for the $h$-th harmonic (with $\omega_{h}=$ $\left.h \cdot \omega_{n}\right)$, the voltage laws of the couple of loops are

$$
\begin{aligned}
& \bar{E}_{A k}=-\left(R_{c e}+R_{r a y}\right) \bar{I}_{A . k-1}-\left(R_{c e}+R_{r a y}\right) \bar{I}_{A . k+1}+ \\
& +2\left(R_{r i m}+R_{c e}+R_{r a y}+j \omega_{h} L_{p \ell} / 2\right) \bar{I}_{A . k}+ \\
& -R_{c e} \bar{I}_{B . k-1}+2 R_{c e} \bar{I}_{B . k}-R_{c e} \bar{I}_{B . k+1}
\end{aligned}
$$

$$
\begin{aligned}
& \bar{E}_{B k}=-\left(R_{c e}+R_{r a y}+R_{c i}\right) \bar{I}_{B . k-1}-\left(R_{c e}+R_{r a y}+R_{c i}\right) \bar{I}_{B . k+1}+ \\
& 2\left(R_{r i m}+R_{c e}+R_{r a y}+j \omega_{h} L_{p \ell} / 2+2 R_{c i}\right) \bar{I}_{B . k}+ \\
& -R_{c e} \bar{I}_{A . k-1}+2 R_{c e} \bar{I}_{A . k}-R_{c e} \bar{I}_{A . k+1}
\end{aligned}
$$

Parasitic loops form a meshed net; to solve it in a rigorous way, the equations of all the loops should be written, and the global system should be solved. Such an approach has been proposed in [30], [31]. Here, an approximated model is proposed, more suited for the general trend analysis here developed, because it is much simpler, being based on a single loop approach. As a matter of fact, the solution of the global system in [30], [31] showed that in a parasitic loop couple, the currents $\bar{I}_{A . k}$ and $\bar{I}_{B . k}$ are just slightly different each other: therefore, we consider only loops type A, and we assume $\bar{I}_{B . k} \approx \bar{I}_{A . k}$. Thus, (18-a) becomes

$$
\begin{aligned}
& \bar{E}_{A k}=-\left(2 R_{c e}+R_{r a y}\right) \bar{I}_{A . k-1}-\left(2 R_{c e}+R_{r a y}\right) \bar{I}_{A . k+1}+ \\
& +2\left(R_{r i m}+2 R_{c e}+R_{r a y}+j \omega_{h} L_{p \ell} / 2\right) \bar{I}_{A . k}
\end{aligned}
$$

The current phasors in the system of parasitic loops behave as the currents in the cage of an induction machine: they are all equal in magnitude, and the displacement between the current phasors of two adjacent loops is always the same. As regards the loop currents, the displacement angle equals twice the slot angle $\alpha_{e}=\left(2 \pi / N_{t}\right) \cdot(p / 2)$

$$
\alpha_{e}\left(P_{t}, N_{t c p h}\right)=\frac{2 \pi}{N_{t}\left(P_{t}, N_{t c p h}\right)} \frac{p}{2}
$$

Thus, the currents in the loops $k-1$ and $k+1$ can be expressed as

$$
\bar{I}_{A . k-1}=\bar{I}_{A . k} \exp \left(j 2 \alpha_{e}\right) \quad \bar{I}_{A . k+1}=\bar{I}_{A . k} \exp \left(-j 2 \alpha_{e}\right)
$$

and (19) becomes $\bar{E}_{A k}=\bar{Z}_{e q} \bar{I}_{A . k}$, where

$$
\bar{Z}_{e q}=\left\{\begin{array}{l}
2\left(R_{r i m}+2 R_{c e}+R_{r a y}+j \omega_{h} L_{p \ell} / 2\right)+ \\
-\left(2 R_{c e}+R_{r a y}\right)\left[\exp \left(j 2 \alpha_{e}\right)+\exp \left(-j 2 \alpha_{e}\right)\right]
\end{array}\right\}
$$

The equivalent impedance (22) allows to obtain the loop current $\bar{I}_{A . k}$ very quickly; moreover, it has been verified that the error with respect to the solution of the global system in [30], [31] is very little (for the fundamental, lower than $0.1 \%$ ).

By making explicit the functional dependencies, we have

$$
\begin{array}{r}
\bar{Z}_{e q}\left(P_{t}, N_{t c p h}, h\right)=2\left(\begin{array}{l}
R_{r i m}+2 R_{c e}+R_{r a y}+ \\
j \omega_{h}\left(P_{t}, N_{t c p h}\right) L_{p \ell}\left(P_{t}, N_{t c p h}\right) / 2
\end{array}\right)+ \\
-\left(2 R_{c e}+R_{r a y}\right)\left[\begin{array}{l}
\exp \left(j 2 \alpha_{e}\left(P_{t}, N_{t c p h}\right)\right)+ \\
+\exp \left(-j 2 \alpha_{e}\left(P_{t}, N_{t c p h}\right)\right)
\end{array}\right]
\end{array}
$$

Similarly to Table IV, Table V reports the values of the equivalent impedance magnitude (for the fundamental component, i.e. $h=1$ ), evaluated when the geometrical sizes are obtained from the model (1)-(15) or are the actual sizes of the prototypes; in other words, (23) is evaluated by putting in it the data labeled "model" in Tab. IV, or the data labeled "prototype".

Fig. 10 shows graphically the trends of the impedance magnitude (continuous lines) with the machine power, together with the prototype values (markers). Again, the 
This is the author's version of an article that has been published in this journal. Changes were made to this version by the publisher prior to publication. The final version of record is available at http://dx.doi.org/10.1109/TIE.2015.2511086

discontinuities in the plots are due to the Round functions used in equation (5).

TABLE V

EQUIVALENT IMPEDANCE (22)-(23) MAGNITUDE [ $\mu \Omega]$ COMPARISON BETWEEN THE MODEL AND THE PROTOTYPE VALUES

\begin{tabular}{l|r|l}
\hline \hline \multirow{2}{*}{$50 \mathrm{~kW}$} & model & $\left|\bar{Z}_{e q}(50 \mathrm{e} 3,6,1)\right|=420$ \\
\cline { 2 - 3 } & prototype & $\left|\bar{Z}_{e q 50}\right|=313$ \\
\hline \multirow{2}{*}{$200 \mathrm{~kW}$} & model & $\left|\bar{Z}_{e q}(200 \mathrm{e} 3,4,1)\right|=515$ \\
\cline { 2 - 3 } & prototype & $\left|\bar{Z}_{e q 200}\right|=504$ \\
\hline \hline
\end{tabular}

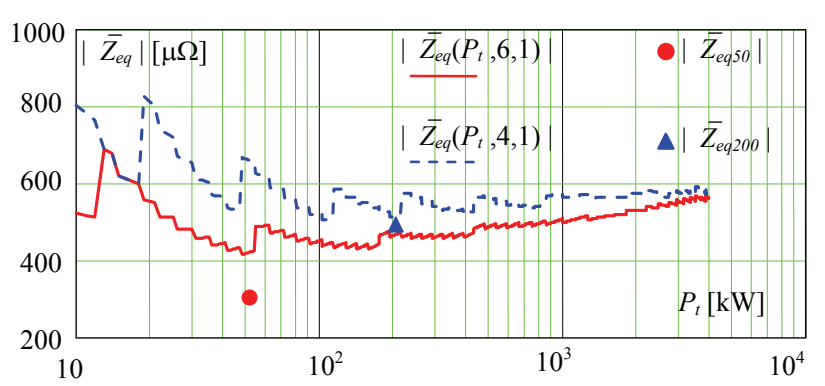

Fig. 10. Trend of the equivalent impedance $Z_{e q}(22)-(23)$, as a function of the machine power (lines), together with the prototype values (markers).

Note that even if the model and the prototype resistances are rather different from each other (see values in Tab IV), the model and the prototype impedances are rather similar. This is due to the way how the several terms combine in (23) to give the equivalent impedance $Z_{e q}$, together with the fact that (as previously noted) the difference between the model and the prototype resistances is not always in the same way.

Thus, a perfect quantitative matching of prototype and model results for current and losses is not guaranteed. However, rather than an accurate evaluation of parasitic currents and losses, the aim of the model is the analysis of their general trend with the machine power and the understanding of scale effects. In addition, the precise computation of parasitic losses at the design stage needs accurate knowledge of steel resistivity and contact resistances at the interface between different elements included into parasitic loops. As known, resistivity in semifinished steel products can undergo significant fluctuations, and modelling contact resistances accurately is highly challenging.

\section{EMFs AND PARASITIC CURRENTS EVALUATION}

From [30], the rms value $E_{p \ell h}$ of the $h$-th harmonic of the parasitic loop EMF is expressed by

$$
E_{p \ell h}=k_{t h} \cdot 2 \cdot 2 \pi h f_{n} \cdot \frac{\Phi_{t h}}{\sqrt{2}}
$$

where $\Phi_{t h}$ is the $h$-th harmonic of the tooth flux (peak value of the phasor) and $k_{t h}$ is a composition factor of the fluxes of two adjacent teeth:

$$
k_{t h}=\left|\cos \left(h \cdot \pi \cdot \frac{3 \cdot N_{t c p h}+1}{6 \cdot N_{t c p h}}\right)\right| .
$$

Another outcome of the analysis performed in [30] by means of the global system was that the contribution of the EMF harmonics to the parasitic currents is minor (about 7$8 \%$ ). Thus, in order to have a quick and simple estimation of the parasitic current amount, only the fundamental parasitic loop EMF can be considered. Its rms value equals

$$
E_{p \ell 1}=\left|\sin \left(\frac{\pi}{6} \cdot \frac{1}{N_{t c p h}}\right)\right| 2 \cdot 2 \pi f_{n} \cdot \frac{\Phi_{t 1}}{\sqrt{2}}
$$

The fundamental $\Phi_{t 1}$ of the tooth flux can be assumed equal to the peak value of the no-load tooth flux $\Phi_{t p}$, occurring when the tooth axis is aligned to the PM axis [18]. It can be expressed [18] as

$$
\Phi_{t p}=\frac{A_{g}}{p} \alpha_{m} B_{m}
$$

By means of the relation $N_{n}=120 \cdot f_{n} / p$, the rms value $E_{p \ell 1}$ of the fundamental of the parasitic loop EMF results

$$
\begin{aligned}
& E_{p \ell 1}\left(P_{t}, N_{t c p h}\right)= \\
& \left|\sin \left(\frac{\pi}{6} \frac{1}{N_{t c p h}}\right)\right| N_{n}\left(P_{t}\right) \frac{\pi}{30} \frac{\pi}{4 \sqrt{2}} \alpha_{m} B_{m}\left(1-k_{D}{ }^{2}\right) D_{e}\left(P_{t}\right)^{2}
\end{aligned}
$$

Table VI reports the values of $E_{p \ell 1}$ (28) gained from the model (i.e., by using (1)-(2) for functions $N_{n}\left(P_{t}\right)$ and $D_{e}\left(P_{t}\right)$ in (28) ) and from the prototypes (i.e., by using the values of $N_{n}$ and $D_{e}$ of the prototypes); Fig. 11 shows graphically the trends of $E_{p \ell 1}$ (continuous lines) with the machine power, together with the prototype values (markers).

TABLE VI

RMS OF THE FUNDAMENTAL OF THE PARASITIC LOOP EMF (28) [mV] COMPARISON BETWEEN THE MODEL AND THE PROTOTYPE VALUES

\begin{tabular}{c|c|c}
\hline \hline \multirow{2}{*}{$50 \mathrm{~kW}$} & model & $E_{p \ell 1}(50 \mathrm{e} 3,6)=86$ \\
\cline { 2 - 3 } & prototype & $E_{p \ell 1.50}=81$ \\
\hline \multirow{2}{*}{$200 \mathrm{~kW}$} & model & $E_{p \ell 1}(200 \mathrm{e} 3,4)=265$ \\
\cline { 2 - 3 } & prototype & $E_{p \ell 1.200}=256$ \\
\hline \hline
\end{tabular}

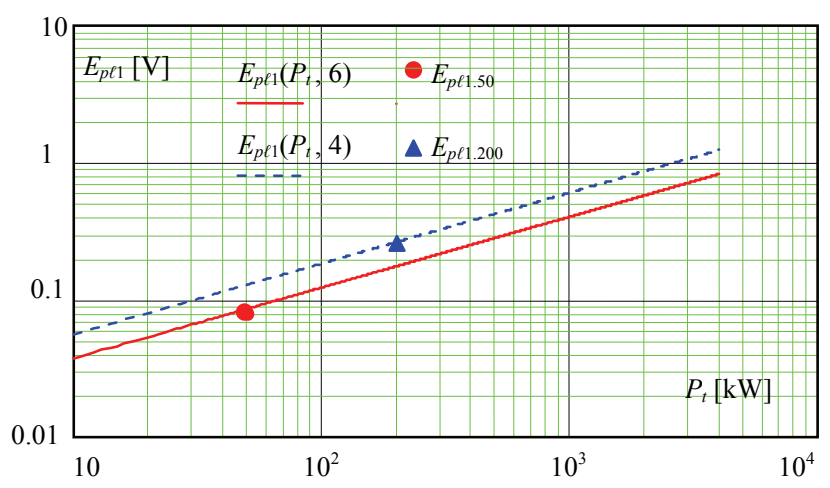

Fig. 11. Trend of the rms value of the fundamental EMF of the parasitic loop $E_{p \ell 1}$ (28), as a function of the machine power (continuous lines), together with the prototype values (markers).

Now, the currents in all the branches of the parasitic loops can be evaluated quickly. In particular, the magnitude of the rms fundamental current are evaluated as follows:

- the current $I_{\text {loop. } 1}$ in one loop is given by:

$$
I_{\text {loop. } 1}\left(P_{t}, N_{t c p h}\right)=\frac{E_{p \ell 1}\left(P_{t}, N_{t c p h}\right)}{Z_{e q}\left(P_{t}, N_{t c p h}, 1\right)} ;
$$

- the current $I_{\text {ray. } 1}$ in one ray is given by the phasor composition of the currents of two adjacent loops: 


$$
I_{\text {ray. } 1}\left(P_{t}, N_{\text {tcph }}\right)=2\left|\sin \left(\alpha_{e}\left(P_{t}, N_{\text {tcph }}\right)\right)\right| I_{\text {loop. } 1}\left(P_{t}, N_{\text {tcph }}\right) ;
$$

- the current $I_{c y l .1}$ in the external cylindrical spacer (object 5 in Figs. 4 and 6) is the sum of the currents in loops A and $\mathrm{B}$ (related to the same couple of teeth); since we assumed $\bar{I}_{B . k}=\bar{I}_{A . k}$, we obtain simply

$$
I_{c y l .1}\left(P_{t}, N_{t c p h}\right)=2 I_{\text {ray.1 }}\left(P_{t}, N_{t c p h}\right) .
$$

Table VII reports the values of these three currents (29)-(31) from the model and from the prototypes. Tab. VII comes directly from Tab. V and VI: the model values of $I_{\text {loop. } 1}$ in Tab. VII are obtained by using in (29) the model values of $E_{p \ell 1}$ and $Z_{e q}$ reported in Tab. V and VI; in the same way, the prototypes values of $I_{\text {loop. } 1}$ are obtained by using in (29) the prototype values of Tab. $\mathrm{V}$ and $\mathrm{VI} ; I_{\text {rav. } 1}$ and $I_{c y l .1}$ derive from (30)-(31). Fig. 12 shows graphically the trend of $I_{c y l .1}$ (31) as a function of the machine power (lines), together with the prototype values (markers).

TABLE VII

MAGNITUDE OF THE RMS FUNDAMENTAL CURRENT (29)-(31) IN SOME BRANCHES OF THE PARASITIC LOOPS [A $\mathrm{A}_{\mathrm{rms}}$ ]

COMPARISON BETWEEN THE MODEL AND THE PROTOTYPE VALUES

\begin{tabular}{c|c|c|c|c}
\hline \hline \multicolumn{2}{c|}{} & $I_{\text {loop. } 1}$ & $I_{\text {ray. } 1}$ & $I_{c y l .1}$ \\
\hline \multirow{2}{*}{$50 \mathrm{~kW}$} & $\begin{array}{c}\text { model } \\
\left(N_{t c p h}=6, P_{t}=50 \mathrm{~kW}\right)\end{array}$ & 205 & 58.5 & 117 \\
\cline { 2 - 5 } & prototype & 258 & 89.7 & 179 \\
\hline \multirow{2}{*}{$200 \mathrm{~kW}$} & $\begin{array}{c}\text { model } \\
\left(N_{t c p h}=4, P_{t}=200 \mathrm{~kW}\right)\end{array}$ & 513 & 246 & 491 \\
\cline { 2 - 5 } & prototype & 507 & 262 & 525 \\
\hline \hline
\end{tabular}

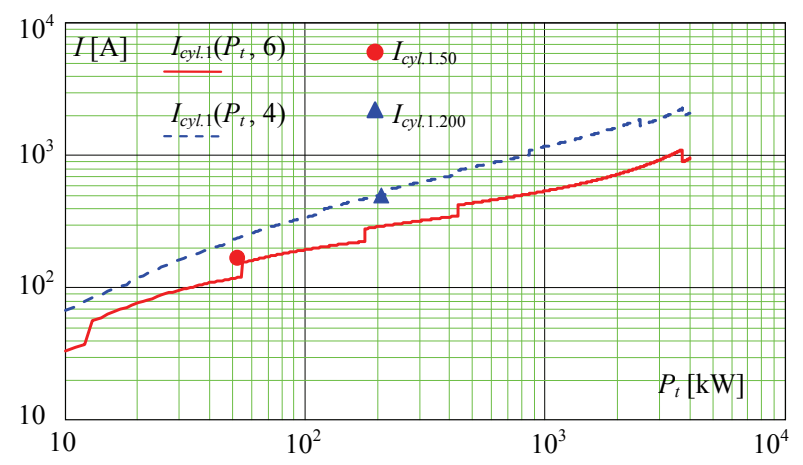

Fig. 12. Trend of the rms value of the fundamental currents in the external cylindrical spacers $I_{c y l .1}$ (31), as a function of the machine power (continuous lines), together with the prototype values (markers).

Figs. 10-12 show clearly that, as the power increases, the impedance of parasitic loops tends to become constant, whereas the EMF increases, thus the parasitic current increases too, and it can reach very high values (up to 1-2 kA for $P_{t}$ in the MWs range). This suggests that with the power increase, the problem of the parasitic current becomes more critical, also in terms of corresponding losses and overheating. In particular, according to the single loop model in Fig. 9, Joule losses due to the fundamental components of parasitic currents can be estimated by (32):

$$
P_{l o s s .1}=\frac{N_{t}}{2}\left[2 \cdot 2 R_{\text {rim }} I_{\text {loop } .1}^{2}+\left(2 R_{\text {ray }}+R_{c i}\right){I_{\text {ray } .1}}^{2}+R_{c e} I_{c y l .1}{ }^{2}\right]
$$

All quantities in (32) depend on $P_{t}$ and $N_{t c p h}$. By substituting in (32) the expressions of the currents (29)-(31) and of the resistances (17), the expression of the function $P_{\text {loss } 1}\left(P_{t}, N_{t c p h}\right)$ is gained. Fig. 13 shows the trends of $P_{\text {loss } 1}$ as a function of the machine power (lines), together with the prototype values (markers). The prototype values have been evaluated by substituting in (32) the prototype currents in Tab.VII and the prototype resistances in Tab IV.

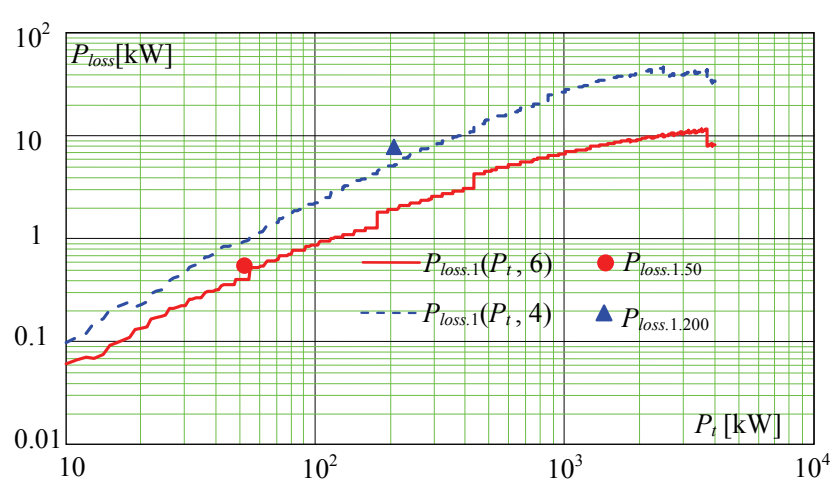

Fig. 13. Trend of the joule losses (due to the fundamental components of the parasitic currents) $P_{\text {loss. } 1}$ (32), as a function of the machine power (continuous lines), together with the prototype values (markers).

Fig. 13 confirms the expectation about the losses due to the parasitic currents, and suggests that appropriate countermeasures have to be taken in order to open the parasitic loops. Being additional losses roughly independent of the delivered power, they are strongly detrimental for the efficiency at medium and low load: namely in the most usual operating conditions of a wind generator. Thus, the negative impact on the annual amount of energy production is expected to be significant.

The solution which will be tested in the next prototypes is the deposition of oxide layers on the rays surfaces in contact with the internal spacers (objects 6 in Figs. 4 and 6). In spite of its apparent simplicity, such a procedure involves some technological issues, mainly due to the extremely high contact stresses at the interface. Thus, special insulating layer materials with high resistance to wear should be selected, as wear may occur both during the machine assembly process and during operation, because of vibrations and additional stress at load.

\section{CONCLUSION}

This paper has analyzed the impact of scale effects on the circulation of parasitic currents in the stator frame structure of some YASA AFPM machines. A model has been developed to estimate the trend of the currents in the parasitic loops as a function of the machine power rating. The analysis has shown that as the power increases, the parasitic currents may increase very much, up to and over $1 \mathrm{kA}$ when the machine power reaches the MWs range. The trend of additional Joule losses produced by parasitic currents has also been evaluated. The detrimental effects of parasitic currents require the parasitic paths to be interrupted. The most promising solution seems the adoption of oxide layers, with high resistance to wear, to be placed in a few structural joints, in suited positions of the parasitic loops.

\section{REFERENCES}

[1] J.F. Gieras, Rong-Jie Wang, M.J. Kamper, "Axial Flux Permanent Magnet Brushless Machines," $2^{\text {nd }}$ Edition, Springer, 2008.

[2] G. De Donato, F.G. Capponi, G. Borocci, F. Caricchi, L. Beneduce, L. Fratelli, A. Tarantino, " $\Omega$-Shaped Axial-Flux Permanent-Magnet Machine for Direct-Drive Applications With Constrained Shaft Height," IEEE Trans. Ind. App., vol.51, no.4, pp.3050-3058, July- 
This is the author's version of an article that has been published in this journal. Changes were made to this version by the publisher prior to publication. The final version of record is available at http://dx.doi.org/10.1109/TIE.2015.2511086

Aug. 2015.

[3] Fei Zhao, T.A. Lipo, Byung-il Kwon, "A Novel Dual-Stator AxialFlux Spoke-Type Permanent Magnet Vernier Machine for DirectDrive Applications," IEEE Trans. Mag., vol.50, no.11, pp.1-4, Nov. 2014.

[4] W. Zhao, T.A. Lipo, B. Kwon, "A Novel Dual-Rotor, Axial Field, Fault-Tolerant Flux Switching Permanent Magnet Machine with High Torque Performance," IEEE Trans. Mag., Early Access.

[5] Wenliang Zhao; T.A. Lipo, Byung-il Kwon, "Comparative Study on Novel Dual Stator Radial Flux and Axial Flux Permanent Magnet Motors With Ferrite Magnets for Traction Application," IEEE Trans. Mag., vol.50, no.11, pp.1-4, Nov. 2014.

[6] O. Maloberti, R. Figueredo, C. Marchand, Y. Choua, D. Condamin, L. Kobylanski, E. Bomme, "3-D-2-D Dynamic Magnetic Modeling of an Axial Flux Permanent Magnet Motor With Soft Magnetic Composites for Hybrid Electric Vehicles," IEEE Trans. Mag., vol.50, no.6, pp.1-11, June 2014.

[7] Yee-Pien Yang; Chung-Han Lee; Po-Chang Hung, "Multi-objective optimal design of an axial-flux permanent-magnet wheel motor for electric scooters," IET Electric Power Applications, vol.8, no.1, pp.1-12, January 2014.

[8] Yu-Seop Park; Seok-Myeong Jang; Ji-Hwan Choi; Jang-Young Choi; Dae-Joon You, "Characteristic Analysis on Axial Flux Permanent Magnet Synchronous Generator Considering Wind Turbine Characteristics According to Wind Speed for Small-Scale Power Application," IEEE Trans. Mag., vol.48, no.11, pp.29372940, Nov. 2012.

[9] S. Djebarri, J.F. Charpentier, F. Scuiller, M. Benbouzid, "Design and Performance Analysis of Double Stator Axial Flux PM Generator for Rim Driven Marine Current Turbines," IEEE Journal of Oceanic Engin., Early Access.

[10] S. Huang, T.A. Lipo, "Axial Flux Permanent Magnet Disc Machines: A Review," International Symposium on Power Electronics, Electrical Drives, Automation, and Motion (SPEEDAM) 2004, Capri, Italy, June 16-18, 2004.

[11] S. Kahourzade, A. Mahmoudi, Hew Wooi Ping; M.N. Uddin, "A Comprehensive Review of Axial-Flux Permanent-Magnet Machines," Canadian Journal of Electrical and Computer Engineering, , vol.37, no.1, pp.19-33, winter 2014.

[12] F. Giulii Capponi, G. De Donato, F. Caricchi, "Recent Advances in Axial-Flux Permanent-Magnet Machine Technology," IEEE Trans. Ind. App., vol.48, no.6, pp.2190-2205, Nov.-Dec. 2012.

[13] F. Giulii Capponi, G. De Donato, A. Rivellini, F. Caricchi, "Fractional-Slot Concentrated-Winding Axial-Flux PermanentMagnet Machine With Tooth-Wound Coils," IEEE Trans. Ind. Appl., vol.50, no.4, pp.2446,2457, July-Aug. 2014.

[14] Sang-Ho Lee; Do-Jin Kim; Jung-Pyo Hong; Jun-Hong Park, "Characteristic Comparison Between the Spiral and the Lamination Stator in Axial Field Slotless Machines," IEEE Trans. Mag., vol.45, no.10, pp.4547-4549, Oct. 2009.

[15] T.J. Woolmer, M.D. McCulloch, "Analysis of the Yokeless And Segmented Armature Machine," IEEE International Conference on Electric Machines \& Drives, IEMDC '07, vol.1, pp.704-708, 3-5 May 2007.

[16] W. Fei, P. Luk, K. Jinupun, "A new axial flux permanent magnet Segmented-Armature-Torus machine for in-wheel direct drive applications," IEEE Power Electronics Specialists Conference PESC 2008, 15-19 June 2008, pp.2197-2202.

[17] H. Vansompel, P. Sergeant, L. Dupre, A. Van den Bossche, "Evaluation of a Simple Lamination Stacking Method for the Teeth of an Axial Flux Permanent-Magnet Synchronous Machine With Concentrated Stator Windings," IEEE Trans. Mag., vol.48, no.2, pp.999-1002, Feb. 2012.

[18] A. Di Gerlando, G. M. Foglia, M. F. Iacchetti, R. Perini, "Axial Flux PM Machines With Concentrated Armature Windings: Design Analysis and Test Validation of Wind Energy Generators," IEEE Trans. Ind. Electron., vol.58, no.9, pp.3795-3805, Sept. 2011.

[19] P. Sergeant, H. Vansompel, L. Dupre, "Performance and implementation issues considering the use of thin laminated steel sheets in segmented armature axial-flux PM machines," Intern. Conf. on Electrical Machines (ICEM) 2014, Berlin, 2-5 Sept. 2014, pp.1363-1369.

[20] H. Vansompel, P. Sergeant, L. Dupre, A. Van den Bossche, "AxialFlux PM Machines With Variable Air Gap," IEEE Trans. Ind. Electron., vol.61, no.2, pp.730-737, Feb. 2014.

[21] Takahiko Miura, Shinji Chino, Masatsugu Takemoto, Satoshi Ogasawara, Akira Chiba, Nobukazu Hoshi, "A Ferrite Permanent Magnet Axial Gap Motor with Segmented Rotor Structure for the Next Generation Hybrid Vehicle," XIX Intern. Conf. on Electrical Machines - ICEM 2010, Rome, ITALY, September 6-8, 2010, paper
RF-014338.

[22] Bo Zhang, Yizhe Wang, M. Doppelbauer, M. Gregor, "Mechanical construction and analysis of an axial flux segmented armature torus machine," Intern. Conf. on Electrical Machines (ICEM) 2014, Berlin, 2-5 Sept. 2014, pp.1293-1299.

[23] H. Vansompel, P. Sergeant, L. Dupre, "Optimized Design Considering the Mass Influence of an Axial Flux Permanent-Magnet Synchronous Generator With Concentrated Pole Windings," IEEE Trans. Mag., vol.46, no.12, pp.4101-4107, Dec. 2010.

[24] Electric Machine - Modular, by Nicholas Carpenter, Simon Dowson, Tim Woolmer, Chee Yeow Leong, William Treharne, Malcolm McCulloch, (2011, Dec. 22), Patent Application PCT/GB2010/050236, Pub. No. US 2011/0309726 A1.

[25] Electric Machine - Over-Moulding Construction, by Tim Woolmer, Chris Gardner, Jon Barker, (2013, June 13), Patent Application PCT/GB2011/051550, Pub. No.: US 2013/0147291 A1.

[26] YASA Motors Products: http://www.yasamotors.com/products.

[27] J.G Wanjiku, H. Jagau, M.A. Khan, P. Barendse, "A simple core structure for small axial-flux PMSGs," 2011 IEEE International Electric Machines \& Drives Conference (IEMDC), 15-18 May 2011, pp.1510-1515.

[28] A. Di Gerlando, G. Foglia, M. Iacchetti, R. Perini, "Design Criteria of Axial Flux PM Machines for Direct Drive Wind Energy Generation," XIX Intern. Conf. on Electrical Machines ICEM 2010 Rome, ITALY, September 6-8, 2010, Paper No RF-008168.

[29] A. Di Gerlando, G. M. Foglia, M. F. Iacchetti, R. Perini, "Analysis and Test of Diode Rectifiers Solutions in Grid Connected Wind Energy Conversion Systems Employing Modular Permanent Magnet Synchronous Generators," IEEE Trans. Ind. Electron., vol. 59, no. 5, pp. 2135-2146, May 2012.

[30] A. Di Gerlando, G. M. Foglia, R. Perini, M. F. Iacchetti, "Analysis of stray paths for parasitic currents in some topologies of Yokeless and Segmented Armature Axial Flux PM Machines," Intern. Conf. on Electrical Machines (ICEM) 2014, Berlin, 2-5 Sept. 2014, pp.390-395.

[31] A. Di Gerlando, G. M. Foglia, R. Perini, M. F. Iacchetti, "Parasitic Currents in Structural Paths of YASA Axial Flux PM Machines: Estimation and Tests," accepted for publication in IEEE Trans. Energy Conv.

[32] A. Di Gerlando, G. M. Foglia, R. Perini, M. F. Iacchetti, "Effects of Manufacturing Imperfections in Concentrated Coil Axial Flux PM Machines: Evaluation and Tests," IEEE Trans. Ind. Electron., Vol. 61, no. 9, pp. 5012-5024, Sept. 2014.

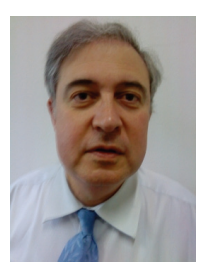

Antonino Di Gerlando (M'93) received his MS degree in electrical engineering from the Politecnico di Milano, Italy, in 1981. Currently, he is a Full Professor at the Department of Energy at Politecnico di Milano. Fields of interest: design and modeling of electrical machines, converters and drive systems. He is a member of IEEE, of the Italian Association of the Electric and Electronic Engineers (AEI), of the Electric Italian Committee of Standards (CEI) and of the SC of ICEM Conference.

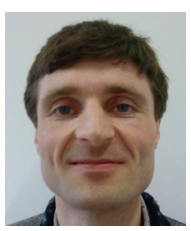

Giovanni Maria Foglia received his MS degree and the $\mathrm{PhD}$ in electrical engineering at Politecnico di Milano, Milano, Italy, in 1997 and 2000.

Currently, he is an Assistant Professor at the Department of Energy at Politecnico di Milano, and his main field of interest is the analysis and design of PM electrical machines.

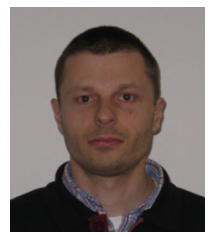

Matteo Felice Iacchetti (M'10) received the $\mathrm{PhD}$ in electrical engineering from the Politecnico di Milano, Milano, in 2008.

Currently, he is a Lecturer with the School of Electrical and Electronic Engineering at The University of Manchester, Manchester, UK. His main research interests are the design, modeling and control of electrical machines.

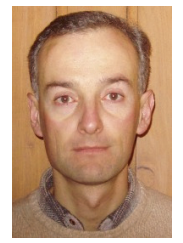

Roberto Perini (M'10) received his MS degree and the $\mathrm{PhD}$ in electrical engineering from the Politecnico di Milano, Milano, Italy.

Currently, he is an Associate Professor at the Department of Energy at Politecnico di Milano. His interests are in the design and modeling of electrical machines and wind energy conversion system. 